\title{
Coexistent Pulmonary Tuberculosis and Carcinoma Lung Diagnosed from the Same Clinical Specimen - A Case Report
}

Abin VT ${ }^{1 *}$, Arjun $\mathrm{P}^{1}$, Ameer KA ${ }^{1}$, Leena Devi KR ${ }^{2}$, Biji KA² and Jaiprakash Madhavan ${ }^{3}$

${ }^{1}$ Department of Respiratory Medicine, Kerala Institute of Medical Sciences, Trivandrum, India

${ }^{2}$ Department of Pathology, Kerala Institute of Medical Sciences, Trivandrum, India

${ }^{3}$ Department of Oncology, Kerala Institute of Medical Sciences, Trivandrum, India

\begin{abstract}
The presence of both Tuberculosis and primary lung cancer in the same person is extremely rare phenomenon. Tuberculosis has been known to occur during the treatment of lung malignancy due to immunosuppression but the simultaneous demonstration of both etiologies in same biopsy during investigation of pleural effusion is extremely uncommon.
\end{abstract}

Keywords: Pleural effusion; Coexisting; Tuberculosis; Malignant

\section{Introduction}

Although Tuberculosis and malignancy are the common causes of pleural effusion the coexistence of both the diseases in same person is an extremely rare phenomenon. Tuberculosis has been documented to occur in patients who have undergone chemotherapy for malignancy [1]. But diagnosis of both the disease concomitantly in the initial presentation itself is very rare. Herein we present the case of a 72 year old male who presented with left sided pleural effusion and on investigation was found to have features of both $\mathrm{TB}$ and primary lung malignancy in the same pleural biopsy specimen

\section{Case History}

72 year old male known hypertensive and diabetic presented to our hospital with complaints of generalized weakness and tiredness of 2 weeks duration. He had fever, cough to start with, but subsided on symptomatic treatment from a local doctor. He also gave history of progressive weight loss over the past 2 month. General examination of the patient was unremarkable. Examination of the respiratory system revealed absent air entry over the left infraaxillary and infrascapular areas. Examination of other systems was within normal limits.

Lab investigations revealed normal blood counts. Liver function test were normal apart from elevated alkaline phosphatase levels (224U/l). He had hyponatremia, Na-129. Renal function tests were normal. Chest radiograph posterior anterior view was suggestive of left sided pleural effusion with infiltrates in left upper zone (Figure 1). He was evaluated with CT thorax which showed a nodular lesion with speculated margin in apical segment of left upper lobe which was radiographically suggestive of primary neoplasm (Figure 2). There was evidence of left sided pleural effusion (Figure 3).

USG abdomen did not reveal any intraabdominal pathology.

He underwent pleural aspiration and $700 \mathrm{ml}$ of straw colored fluid was aspirated and the pleural fluid was lymphocyte predominant exudates and no malignant cells were seen. The details of which are given in Table 1.

\section{Gene Xpert for Mycobacterium tubrculosis also came as negative.}

Pleural biopsy was also done using Cope's needle which revealed fragments of fibrocollagenous tissue showing ill defined granulomas composed of epitheloid cells, Langhans giant cells and lymphocytes. This was suggestive of granulomatous inflammation (Figure 4). Deeper sections of a fragment of tissue revealed a few large spindle cells with pleomorphic vesicular nuclei and prominent nucleoli. There was

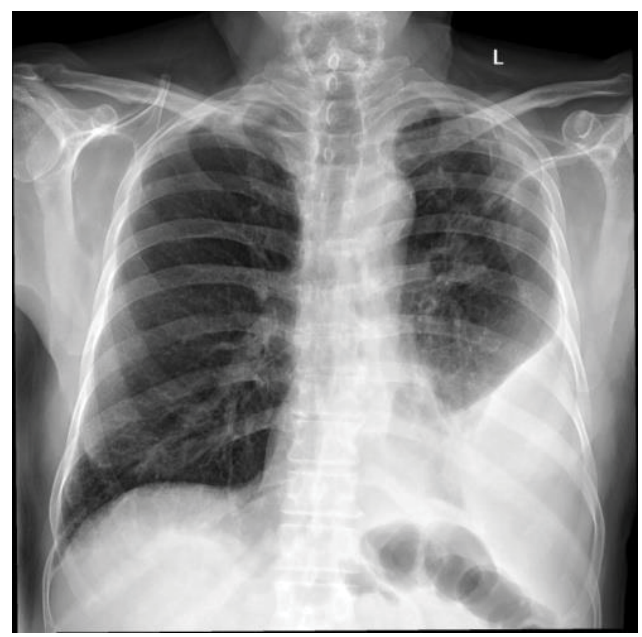

Figure 1: Chest radiograph posterior anterior view was suggestive of left sided pleural effusion with infiltrates in left upper zone.

suspicion of epithelial neoplasm, IHC was done. IHC for Calretinin and pan CK were done first. Scanty tissue fragments showing spindle cells, were seen in Calretinin(negative) and in pan CK(positive) (Figure 5). Ideally, CK7, CK20, CK5/6 and TTF1 would have been done when a carcinoma of pulmonary origin was suspected. These are done to know whether the carcinoma can be further classified into adenocarcinoma or squamous cell type. But in the paraffin block, no more tissue was available to perform any further studies. So the final report was given as consistent with coexisting tuberculosis with a malignant epithelial neoplasm. Further workup for distal metastasis did not reveal any evidence of secondaries in bone, abdomen or brain. Patient was initiated on ATT and since he was also found as having Stage IV Ca lung, he was

*Corresponding author: Abin VT, Resident, Department of Respiratory Medicine, Kerala Institute of Medical Sciences, Trivandrum, India, Tel: 00919447323742; E-mail: abinvat@gmail.com

Received May 21, 2014; Accepted July 15, 2015; Published July 20, 2015

Citation: Abin VT, Arjun P, Ameer KA, Leena Devi KR, Biji KA, et al. (2015) Coexistent Pulmonary Tuberculosis and Carcinoma Lung Diagnosed from the Same Clinical Specimen - A Case Report. J Pulm Respir Med 5: 274. doi:10.4172/2161105X.1000274

Copyright: ( 2015 Abin VT, et al. This is an open-access article distributed under the terms of the Creative Commons Attribution License, which permits unrestricted use, distribution, and reproduction in any medium, provided the original author and source are credited. 


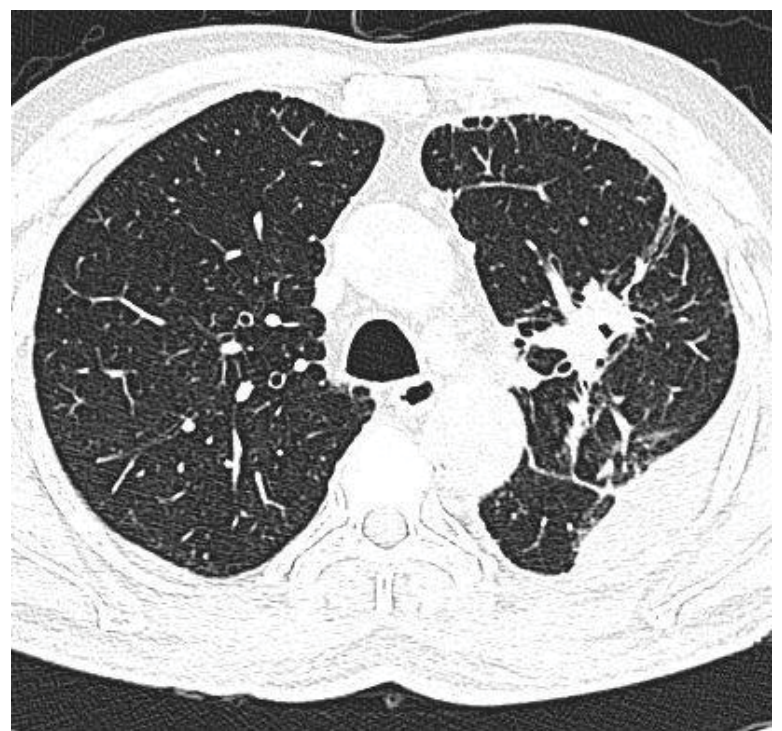

Figure 2: HRCT Thorax lung window showing nodular lesion with spiculated margins in apical segments of left upper lobe.

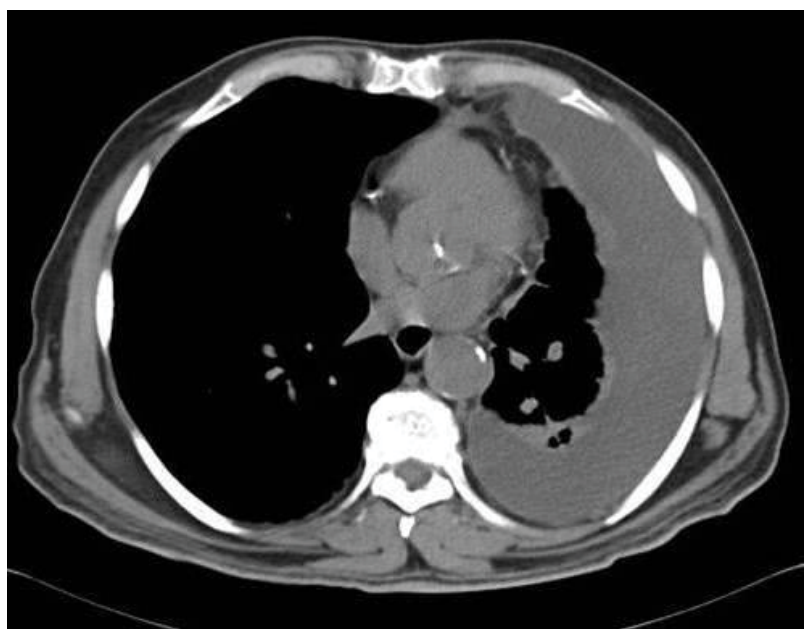

Figure 3: HRCT Thorax soft tissue window showing pleural effusion.

\begin{tabular}{|c|c|c|}
\hline Investigation & Pleural Fluid & Serum \\
\hline Total count & 1719 cells $/ \mathrm{mm}^{3}$ & - \\
\hline Differential count & Lymphocytes-98\%, polymorphs-2\% & - \\
\hline Protein & $5.7 \mathrm{mg} / \mathrm{dl}$ & $7.65 \mathrm{mg} / \mathrm{dl}$ \\
\hline Sugar & $138 \mathrm{mg} \%$ & $174 \mathrm{mg} \%$ \\
\hline ADA & 27.9 & - \\
\hline
\end{tabular}

Table 1: Investigation of pleural fluid.

started on chemotherapy with Carboplatin and Pemetrexed.

He has completed both the antitubercular therapy and chemotherapy and he has improved significantly both clinically and radiologically.

\section{Discussion}

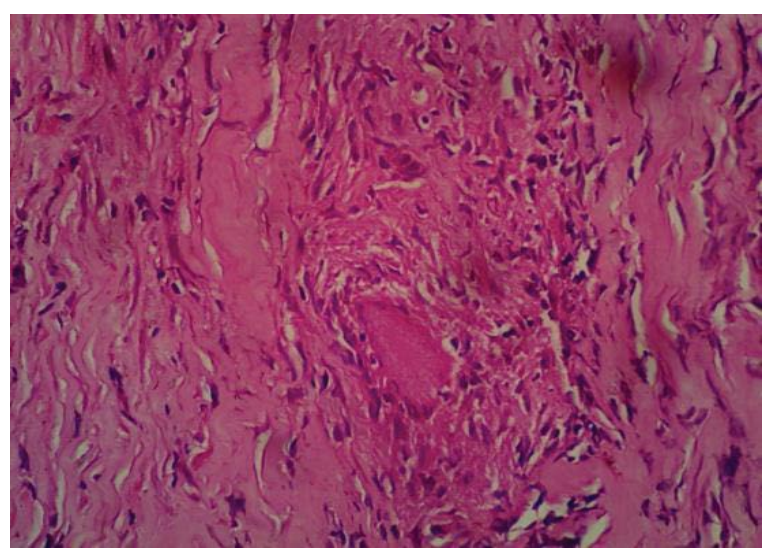

Figure 4: Granuloma, H\&E stain, 400X.

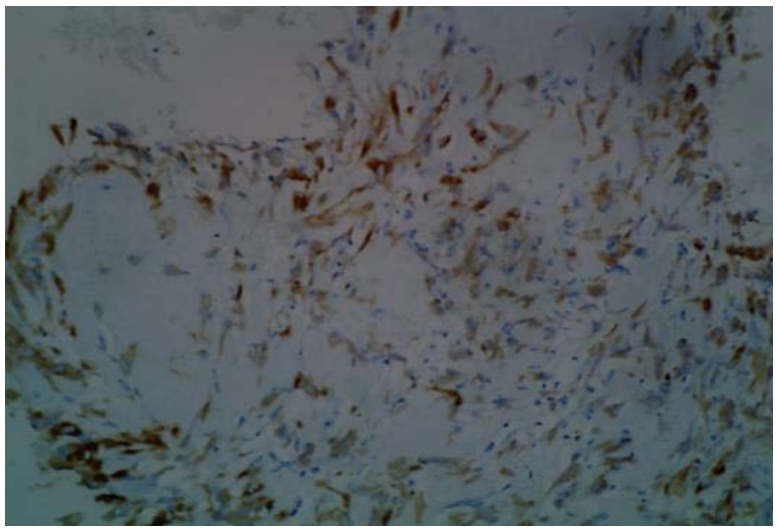

Figure 5: Tumor cells showing cytokeratin positivity 400X.

Tuberculosis and malignancy are the most common of diseases affecting the respiratory system causing significant morbidity and mortality. Although it it common to identify one of them as the etiology of the underlying respiratory disorder very little evidence exists about their coexistence in causing respiratory illness in the same patient. Review of literature looking into the relation betweeen tuberculosis and malignancy shows that the association between tuberculosis and malignancy can be of three types:

1. Development of malignancy on the background of previous tuberculosis [2]

2. Concurrent existence of both tuberculosis and malignancy in same patient $[3,4]$

3. Both diseases mimicking each other because of the multifaceted presentation $[5,6]$

In addition tuberculosis is known to get reactivated in patients who are on chemotherapy for malignancies. Review of literature shows that there are only few casaes reporting the coexistence of malignancy and tuberculosis. Most of them are case reports of tubercular lymphadenopathy detected concurrently with hematological malignancy and metastatic malignacies of breast or gastrointestinal tract. There is only one case report of malignancy in lung with concurrent pleural effusion which was proved as tubercular etiology 
Citation: Abin VT, Arjun P, Ameer KA, Leena Devi KR, Biji KA, et al. (2015) Coexistent Pulmonary Tuberculosis and Carcinoma Lung Diagnosed from the Same Clinical Specimen - A Case Report. J Pulm Respir Med 5: 274. doi:10.4172/2161-105X.1000274

[7]. However in that case report the primary malignacy was in tongue with solitary metastasis to left lung.

The Uniqueness of our case report is that we were able to demonstrate the presence of a dual aetiology in the same specimen (as evidenced by presence of granulomatous inflammation as well as concurrent malignancy as evidenced by presence of malignant cells in pleural tissue which was confirmed by IHC)

Search of published medical literature on the coexistence of both tuberculosis and malignancy and both being demonstrated on the same biopsy specimen did not yield any previous published case reports. As such to the best of our knowledge this is the first case report documenting a dual etiology for pleural effusion. This case report is being published to document this fact and also to highlight the importance of obtaining a tissue diagnosis in all cases of exudative pleural effusion.

\section{References}

1. Kamboj M, Sepkowitz KA (2006) The risk of tuberculosis in patients with cancer Clin Infect Dis 42: 1592-1595.

2. Zheng W, Blot WJ, Liao ML, Wang ZX, Levin LI, et al. (1987) Lung cancer and prior tuberculosis infection in Shanghai. Br J Cancer 56: 501-504.

3. Kim YI, Goo JM, Kim HY, Song JW, Im JG (2001) Coexisting bronchogenic carcinoma and pulmonary tuberculosis in the same lobe: radiologic findings and clinical significance. Korean J Radiol 2: 138-144.

4. Fanourgiakis P, Mylona E, Androulakis II, Eftychiou C, Vryonis E, et al. (2008) Non-Hodgkin's lymphoma and tuberculosis coexistence in the same organs: a report of two cases. Postgrad Med J 84: 276-277.

5. Al-Maghrabi JA, Sawan AS, Kanaan HD (2006) Hodgkin's lymphoma with exuberant granulomatous reaction. Saudi Med J 27: 1905-1907.

6. Ghosh KC, Biswas S, Misra AK, Dhibar T, Das SK (2007) Limbic encephalitis-an uncommon presentation of systemic malignancy. J Assoc Physicians India 55: 731-733.

7. Kobashi Y, Fukuda M, Nakata M, Oka M (2005) Coexistence of metastatic lung cancer and pulmonary tuberculosis diagnosed in the same cavity. Int $\mathrm{J}$ Clin Oncol 10: 366-370 